\title{
Being-in-the-World Reconsidered: Thinking Beyond Absorbed Coping and Detached Rationality
}

\author{
Karl Leidlmair $^{1}$ (D) \\ Published online: 16 December 2019 \\ (c) The Author(s) 2019
}

\begin{abstract}
Recently, a revival of phenomenological approaches has been gaining ground in the literature of cognition and human understanding. Heidegger's Being-in-the-World plays a decisive role here. Instead of viewing the mind as an independent entity separated from the "outer" world, these approaches assert an immediate understanding of a meaningful environment. Such an immediate understanding is seen in the light of embodied practices, when humans are engaged in skillful absorbed coping. An analysis of Heidegger's concept of truth provides a more sophisticated view. Beingin-the-World does not always grant direct access to an immediate understanding of a meaningful environment. Often, other objects in the world conceal themselves from human view. In a first approach, this understanding of truth will be elaborated on the basis of an exegesis of Heidegger's text concerning his question of truth. What this actually means for a phenomenological understanding will be explained by a closer look at two central topics in Being and Time: disturbance and anxiety. The idea is to show that Heidegger's Being-in-the-World—properly interpreted-can offer a "third way" beyond the limits of a mindless coping and an understanding of the mind as a self-standing entity detached from other entities in the world.
\end{abstract}

Keywords Heidegger $\cdot$ Cognitive science $\cdot$ Phenomenology

\section{Absorbed Coping-The Source of the Intelligibility of the World?}

Hubert Dreyfus blames classical cognitive science for holding a distorted view of human understanding that he calls the "Cartesian model". He provides a clear summary of the Cartesian approach, which I want to quote at full length.

"How can (...) senseless physical stimulation be experienced directly as significant? All generally accepted neuro-models fail to help, even when they talk of dynamic coupling, since they still accept the basic Cartesian model, viz.:

Karl Leidlmair

Karl.Leidlmair@uibk.ac.at

1 Institute of Psychology, University of Innsbruck, Innrain 52, 6020 Innsbruck, Austria 
1. The brain receives input from the universe by way of its sense organs (the picture on the retina, the vibrations in the cochlea, the odorant particles in the nasal passages, etc.).

2. Out of this stimulus information, the brain abstracts features, which it uses to construct a representation of the world" (Dreyfus 2009: 58).

The extent to which this conception of perception described by Dreyfus as the "Cartesian model," actually corresponds to what Descartes points out in his own writings, is of minor interest in the context of this paper. Much more important is the relationship between the human mind and its environment as described by this model. Here, the rational "subject" is understood as a self-contained entity thatoperating in the mode of detached rationality - is related to the other "objects" in the outside world only via sensory data (a similar anti-Cartesian approach is suggested by Haugeland 1998: 207). Whereas the Cartesian model ascribes to cognition a passive representation of objects by rational subjects, phenomenology (as long as it can be traced back to Heidegger's Being-in-the-World) implies that "our experience of the everyday world (not the universe) is given as already organized in terms of significance" (Dreyfus 2009: 58). In conformity with the ecological psychology of Gibson it is argued that features of our environment are directly perceived according to the relevance they have for an organism (Dreyfus 2009: 60). Meanings do not arise from the transformation of mindless sensory data into the representational mind. Instead of perceiving "detached" objects of our environment, we directly perceive meaningful objects (see Haugeland 1998: 232). In his book What Computers Still Can't Do Dreyfus asserts that the "meaningful objects (...) among which we live (...) are the world itself' (Dreyfus 1992: 265f.). He understands such a world not as a propositional belief system but as a way of opening us "through our unthinking and unthinkable engaged perception and coping" (Dreyfus 2005: 59). Essential to our being in the world is a tacit practical know-how that we use in the course of solving our problems in everyday life. Our relationship to the surrounding world is therefore in the first place not a theoretical but a practical one. Dreyfus breaks with the Cartesian tradition by taking "Heidegger's new approach" as "a phenomenology of 'mindless' coping skills that is the basis of all intellibility" (Dreyfus 1991: 3). ${ }^{1}$

What is true regarding all that is that Heidegger actually argues for such a direct perception of things when he says: "We never really first perceive a throng of sensations, e.g., tones and noises, in the appearance of things-as this thing-concept alleges; rather we hear the storm whistling in the chimney, we hear the threemotored plane, we hear the Mercedes in immediate distinction from the Volkswagen. Much closer to us than all sensations are the things themselves" (Heidegger 1971: 25).

\footnotetext{
1 A good overview of Dreyfus' deep suspicion of all claims that take conceptuality as "always pervasive and operative" in human understanding can be found in a collection of papers dedicated to the McDowell-Dreyfus Debate; see Schear (2013: 29); Wheeler calls such a kind of everyday cognition "smooth coping"; see Wheeler (2005: 133).
} 
At first glance, it seems to also be true that an explanation for such direct access can be found in humans' involvement in a practical activity in which things show up as ready-to-hand. A closer look at Heidegger's writing, especially on Being and Time, however, reveals that such a pragmatic reading shows only a limited picture of Heidegger's concept of Being-in-the-World: the idea of immediate access to entities in the world is framed within a broader context-a context in which the entities encountered are not always and simply open to view but rather simultaneously disguised.

The open question is what such a concealment of things in conjunction with Heidegger's Being-in-the-World truly means. Does it mean that there are special situations in which we perceive other things as "detached" objects in an external world? Such a view would entail that the opposite of immediate access to entitities can be found in some kind of detached rationality. However, are the opposing pairs "immediate access to things" and "detached rationality" the only alternatives offered by Heidegger's phenomenology?

At any rate, for Dreyfus, the question is "how our absorbed, situated experience comes to be transformed so that we experience context-free, self-sufficient substances with detachable properties" (Dreyfus 2007: 364). A related question is: "How rationality and language grow out of nonconceptual and nonlinguistic coping" (Dreyfus 2005: 61).

With direct reference to Heidegger Dreyfus provides a clear answer in his commentary on Being and Time. Only if there is a disturbance in our transparent coping with things do we begin to represent things from a detached theoretical perspective. "Only when absorbed, ongoing activity is interrupted is there room for such theoretical reflection” (Dreyfus 1991: 79).

However, one serious problem remains. If disturbances can really explain the occurrence of theoretical reflection, the unresolved question is whether such a detached rationality is related to our situated experience "on the ground floor". Is it about an accidental misfortune that disrupts our everyday activities in some situations or do such disturbances belong to the indispensable conditions of humankind? If the former were the case, then theoretical reflection would not belong to the basic structure of human existence. It is Dreyfus (perhaps intending to show the groundlessness and needlessness of Cartesianism) who espouses such a view. In his commentary on Being and Time, he explicitly writes: "A simplified culture in an earthly paradise is conceivable in which the members' skills mesh with the world so well that one need never do anything deliberately or entertain explicit plans and goals" (Dreyfus 1991: 85).

Such a position requires that "mindless" coping skills provide a sufficient ontological description of Dasein. Arguing against such a restrictive reading of Heidegger, I want to show that all those borrowings from Heidegger (such as "mindless coping" and "being absorbed in the task ready at hand") provide only a distorted image of Heidegger's Being-in-the-World. The idea that skillful coping is a means of getting direct access to meaningful objects together with the idea that detached rationality occurs only in rare moments of breakdowns of our absorbed activity do not, or so I believe, cover all aspects of Heidegger's own view of how human beings can relate to other entities. 
Reconstructing Heidegger's "world" (with "world" as a synonym for the horizon against which entities become accessible as entities) first requires an answer to the following two questions:

(a) How can such an immediate directedness towards entities be interpreted against the background of Heidegger's conception of truth? Here, the focus will be primarily on an immanent analysis of the terminology used by Heidegger in Being and Time. Heidegger's construction of truth will be elaborated as a mutual interplay between the immediately disclosed and the undisclosed, between aletheia and lethe. We have to determine what this means for a phenomenological understanding by taking a closer look at two topics in Being and Time: disturbance and anxiety.

(b) In Heidegger's understanding, concealment does not indicate a realm of separate entities cut off from the human mind; on the contrary it is an integral part of human understanding. Such understanding shows up when human skillful coping activities break down (which will be described on the basis of the topics "disturbance" and "anxiety"). However, how can it ever happen that such a "hidden" side of entities can be transformed in a separate realm of entities detached from the human mind? Thus the question is, how detached rationality can ever arise. My point is to show that neither absorbed coping nor detached rationality is an achievable state for humans. With the term "Dasein" Heidegger situates human beings in a dynamic relationship between, on the one hand, human embeddedness in a meaningful context that remains in the background and, on the other hand, the decontextualization of such embeddedness in cases of breakdown.

\section{Heidegger's Question of Truth}

If Dreyfus and others reject representationalism in favor of some kind of direct perception of things, how can non-veridical perceptual states ever arise? The answer to that question depends on what is understood by direct perception. ${ }^{2}$ In the context of this paper, I will focus on the question of what direct perception might be in the light of Heidegger's Being-in-the-World. A contrasting juxtaposition of Heidegger's understanding of truth (or untruth) and the representational theory of mind may be in order.

Beginning with the representational theory of mind, we can ask how a veridical perception and a deception are possible according to that theory. The representational theory of mind implies that we first perceive an irradiation pattern on the retina (using vision as an example) and then afterwards interpret these sensedata as a certain object by creating a representation of the object. The perception is veridical if the internal representation created by the representational mind corresponds to what "should have been created given the external (referent) situation" (Perner 1991: 7). The perception is wrong if the internal representation differs from what ought to be created given the external situation (Perner 1991: 7).

\footnotetext{
${ }^{2}$ Here there are great differences, for example between the arguments of Smith (2002) and those of Heidegger. Discussing these arguments would go beyond the scope of that paper.
} 
Thus the perception is wrong if there is a malfunction in the perceiving subject. Perner, who supports such a representational theory of the mind sees the possibility for deception in conjunction with "the fact that perception is not a direct, infallible imprint of reality but that it has representational qualities"(Perner 1991: 92). Perception does not simply reflect reality but represents it (as something) in a specific way.

In contrast to the representational theory of mind, we now must ask what a veridical perception and a deception are according to Heidegger. For Heidegger, when we assert, we are directly related to things. We immediately perceive things - and not uninterpreted sense data which obtain meaning by the creation of a mental image in our heads. If we make a true assertion such as "the picture on the wall is hanging askew" (Heidegger 1962: 260), that assertion is not true because our mental image of the picture corresponds with the actual picture. It is true, because the thing (the picture) to which I am referring is from the very beginning actually as it appears to me. For an assertion to be true for Heidegger means to discover a being in such a way that it has been all along before its discovery: "The Being-true (truth) of the assertion must be understood as Beinguncovering" (Heidegger 1962: 261). Heidegger initially interprets the Greek aletheia in Being and Time as a process through which a being is snatched out of its hiddenness (Heidegger 1962: 265).

Nevertheless, we must now ask, how can an illusion ever come about if we are through an assertion immediately connected to the things themselves? $?^{3}$ Even in the case of deception, we are immediately related to things and not-as the representational theory of mind maintains - to mere mental images. Perceiving is - as Heidegger emphasizes_- "intrinsically" constituted by the relation to other things "whether that to which it comports as object is or is not extant" (Heidegger 1988: 61). That is why the "intentional Dasein (...) is always already immediately dwelling among things" (Heidegger 1988: 66). If in the darkness we mistake a tree for a human being, Heidegger holds that such a deception entails that "the man himself is given to me and not, say, a representation of the man" (Heidegger 1988: 63). Therefore, "I can apprehend something imaginarily only if, as apprehender, I intend in

\footnotetext{
3 A similar question has been posed by Tugendhat in regard to his criticism of Heidegger's question of truth. If the truth of a proposition is identified with the discovery of being in $\$ 44$ of Being and Time (Heidegger 1962: 218), then Heidegger's concept of truth-according to Tugendhat-would lose its normative meaning. The problem is that Heidegger uses the word "discovering" (Entdecken) in two different ways that are not clearly divided. On the one hand, he uses the word "discovering" according to the Greek "apophainestai" which means as much as "to point out". If the word is used in this way, then every proposition, the true and the false one, would be discovering (Tugendhat 1970: 333). But Heidegger also uses "discovering" in the sense of "aletheuein," indicating that only the true proposition is discovering. When those two meanings of discovering are mixed, even in the case of the wrong proposition, entities "have, in a certain way, been uncovered already, and yet they are still disguised" (Heidegger 1962: 265) In a clear and informative overview of Tugendhat's criticism of Heidegger's concept of truth, Smith (2007: 174) points out the problem relating to the equalization of truth and discovery: "The question that goes unanswered is how disclosedness itself, the opening up of Dasein's historical world, is more than a non-normative event, more than - to draw an analogy - merely illuminating a previously darkened room by flicking on the light switch. This, of course, is precisely Tugendhat's question: in what sense can disclosure itself be true or false in a criticial sense?".
} 
general" (Heidegger 1988: 60). Even in the case of deception I am related to a real entity, but I am not related to the entity as it is itself. Thus, a proposition is wrong because the object to which I am immediately relating is something other than it appears to be. The deception is not a malfunction of perception. The deception is somehow located in the thing from the very beginning.

This strange circumstance may be clarified by the following example. A human being who dissembles his feelings before a counterpart (in German: "sich verstellen"), is probably hiding hostile intentions behind a friendly face. This dissemblance is successful only if we do not perceive muscle contractions (or something similar) in the face of the dissembler but rather perceive only pleasure or good will. The deception is based not on the fact that we are relating only to the representation of a friendly face (with no connection to the real situation), but rather on the fact that we actually perceive a friendly face hiding hostile intentions. The friendly face itself dissembles (verstellt) the hostile intentions, which remain hidden.

Heidegger himself, who pays little attention to direct interaction with other people in Being and Time and other writings, uses the expression "verstellen" to explain how a deception in connection with the natural world of objects is possible. In The Origin of the Work of Art he writes for example: "One being places itself in front of another being, the one helps to hide the other (...) a being appears, but it presents itself as other than it is. This concealment is dissembling" (Heidegger 1971: 52).

Therefore, things do not have a hidden side because our perception is wrong. The opposite is the case: a deception is possible only inasmuch as things have a hidden side (Heidegger 1971: 52; see also Heidegger 1992: 24). We encounter this hidden side not only in situations in which we are subject to a deception, on the contrary, the hidden side is a constant companion in the process of discovering other beings. Hiddenness occurs not only in deception but also in truth. Heidegger expressly declares that every thing we encounter in life withholds itself in "concealedness" (Heidegger 1971: 52). Our direct connection to other beings does not take place on a rigid stage "with a permanently raised curtain" (Heidegger 1971: 52) where things are completely disclosed and encountered without a shadow of mystery. There is on the contrary a dialectic relationship between the disclosed and the undisclosed, between aletheia and lethe, or-as Rufus Duits writes - "Disclosure is the play of disclosure and closure, revealing and veiling" (Duits 2007: 215). If things had only a hidden side or-as Heidegger says - if a "measureless oblivion," i.e., "concealment," prevailed, there would be no room left for aletheia. To put it another way, unconcealedness requires "a measure of withdrawing concealment" (Heidegger 1992: 123).

However, because lethe constitutes a key feature of aletheia, unconcealment cannot be considered a mere "elimination of concealedness" (Heidegger 1992: 124). As distinguished from Being and Time, in which the "alpha" of the Greek aletheia is still interpreted in a privative sense, that is, as an elimination of concealment (according to that view, truth would be a deprivation by which beings are snatched from their concealment), the later Heidegger emphasizes the liberating feature of that prefix. In the process unconcealment, concealment is not removed, on the contrary, it reveals itself as concealment (Heidegger 1992; see also Fräntzki 1987). Characteristic of this new approach to truth is the following statement of Heidegger: "The openness of the open mystery does not consist in solving the mystery, thus 
destroying it, but consists in not touching the concealedness of the simple and essential and letting this concealedness alone in its appearance" (Heidegger 1992: 63).

In summary it can be said that in the course of our discovery of things, we simultaneously discover that these things also have a hidden side. Truth (in Heidegger's terms: unconcealment) is therefore not simply the opposite of concealment, but rather the location where we encounter the hidden side of things. But how is all that possible? What we have done so far is at best exegesis. Two questions arise in this context.

First, how can a direct perception of things according to Heidegger be phenomenologically shown? Why can we for example immediately perceive the tapping woodpecker rather than a noise that will be interpreted in hindsight as the knocking of a woodpecker in the frame of our cognitive apparatus? Why do we already dwell "alongside what is ready-to-hand within-the-world" (Heidegger 1962: 207)?

The second question is even more complicated. How can we figure to ourselves that our perception is somehow directly related to a hidden side of things? How can things hide in such a way that this hiddenness is not simply washed away by its disclosure but can for its part immediately be seen or perceived? To be able to say that the being to which we are referring could be something other than it appears to be, we must have some relationship to that being independent of its appearance. How should we be able to touch what withdraws itself from every immediate touch? How can we long for the "open mystery" — to use Heidegger's phrase-without destroying and demasking it in the very process of that longing?

A satisfactory phenomenological answer to the two questions discussed above can be found only if the meaning of disturbances, breakdowns and-as we will see-anxiety in Heidegger's Being and Time can be clarified.

\section{The Role of Disturbance, Breakdowns and Anxiety in Our Being-in-the-World}

Let us start with the first question. How do we gain direct access to other things? Heidegger's straightforward answer to this question is that humans have a basic familiarity (in German: "Vertrautheit") with things. In the The Fundamental Concepts of Metaphysics Heidegger makes an interesting remark concerning this matter: "The worker bee is familiar with the blossoms it frequents, along with their colour and scent, but it does not know the stamens of these blossoms as stamens" (Heidegger 1995: 193). Whereas the bee has direct access to things (this idea matches Gibson's concept of affordances), it has no access to the things as things. Although Heidegger acknowledges that animals have a relationship with other things (with the stamens, with the rock), it is only human beings who are granted an accessibility to beings as such (Heidegger 1995: 269). The real reason that our perceiving is intrinsically related to other things is based on our intelligibility of being. But what is the underlying meaning? To clarify this aspect in a phenomenological way two issues must be discussed. First, how can we explain such an accessibility to being and second, why is this accessibility an accessibility to being as such. Heidegger provides a solution to the first problem. Things are not detached objects at which we stare in 
a theoretical mode and for which the question arises of how the human mind can come into contact with such isolated things. On the contrary, Heidegger maintains that we encounter things in a practical context. Humans have direct access to other objects because those objects are available. ${ }^{4}$ Heidegger calls this characteristic of being, which we encounter in our everyday life, readiness-to-hand (Heidegger 1962: 98). A hammer, to provide a well-known example, is used in order to do something. We manipulate a hammer in order to construct a shelter. Constructing a shelter in turn has the function of protecting us from a thunderstorm. All these different inorder-to's make up a whole nexus of equipment. Only against the background of a network of things affiliated with each other can availableness-the essential feature of the available-be bestowed on a single piece of equipment. As Heidegger explicitly argues, equipment never exists in isolation. "To the Being of any equipment there always belongs a totality of equipment" (Heidegger 1962: 97). Therefore, seeing things as something simply means that we always understand those things against the background of some kind of totality. An explanation of why we have access to being as such can be found herein.

The totality of equipment can finally be traced back to a being (Dasein) which is not a purpose for something else, but to whose "state of Being" "worldhood" itself belongs (Heidegger 1962: 116). "World" is the ultimate horizon against which entities become accessible as entities within-the-world (Heidegger 1962: 118). Heidegger describes the term "world" in one of his later lectures as "manifestness of beings as such as a whole." It is therefore not implausible "that the uncoveredness of entities within-the-world is grounded in the world's disclosedness" (Heidegger 1962: 263; see also Overgaard 2002: 78). However, how this phenomenon of world may be revealed in a phenomenologically convincing way is still an open question. Heidegger actually admits that for the innerworldly available to be encountered in the world, these referential totalities, which ultimately constitute the "in-order-to" of any equipment, must remain in the background and can no longer be grasped "thematically" (Heidegger 1962: 106). How those referential totalities-and with them the phenomenon of world-can come into view, is described by Heidegger in two different paragraphs of Being and Time.

\footnotetext{
4 According to A.D. Smith, Heidegger's proposal to root our primary relation to the world "in terms of instrumentality" contains "an important error" (Smith 2002: 105): "For what is being suggested is that the only way in which sense-experience can be more than the having of sensations is if it is 'suffused' with concepts" (Smith 2002: 105). The motive behind that criticism is that Smith is seeking a general account of perceptual consciusness, which is common to humans and animals. He is seeking an experience that we (and other animals) must have in order to be sentient in relation to the external world before we start to interpret things in the world $a s$ something for use. It is true, as Smith remarks, that according to Heidegger only humans have a "comportment" towards a "world" (Smith 2002: 104). But that does not mean that an animal cannot have "an own relation" to other things. Heidegger insists only that all entities to which animals are referring to are not entities as entities. Only humans have an understanding of being (see Heidegger 1995: 198). I do not want to decide whether Smith's criticism is justified. Instead, I simply hold that Heidegger's openness to the world has another target. His world-disclosure is not a theory of perception based upon the analysis of sense data. Being involved in a practical activity is not somehow hooked to sensations that we must perceive in advance. The human world, as Heidegger would argue, is not based upon "something purely present-at-hand" (Heidegger 1962: 190).
} 
§16: In our everyday coping with things this essential feature of equipmentbeing intimately involved in a whole nexus of other equipment (Heidegger calls this its worldly character) -lurks beneath the surface. When we are coping at our best, we do not pay attention to the functionality of our equipment. Only in cases of a disturbance in our daily coping with things - when the formerly inconspicuous equipment is damaged, is missing or in the way-does the whole nexus of equipment come to the fore. Heidegger writes: "But when an assignement has been disturbed - when something is unusual for some purpose-then the assignement becomes explicit" (Heidegger 1962: 105). Only when the functionality of a piece of equipment has been disturbed does the formerly inconspicuous "in-order-to" of the equipment gain our attention and only then does the world "announce" itself (Heidegger 1962: 105).

$\S 40$ : The phenomenon of world is revealed-and here in an even more insistent way-in the mood of anxiety. In this mood "the totality of involvements of the ready-to-hand and the present-at-hand discovered within-the-world (...) collapses into itself" and "the world has the character of completely lacking significance" (Heidegger 1962: 231). What happens now, is that "on the basis of this insignificance of what is within-the-world, the world in its worldhood is all that still obtrudes itself" (Heidgger 1962: 231). Therefore,-Heidegger concludes,-anxiety discloses "as a mode of state-of-mind" [Befindlichkeit] "first and foremost" the "world as a world" (Heidegger 1962: 232). ${ }^{5}$ However, how is this even possible? How can the world be disclosed first and foremost by anxiety if it already announces itself in the disturbances of the available? Heidegger's meaning is not quite clear. Being and Time does not provide a satisfying explanation, which forces us to interpretation. The comparison of what announces itself through the different stages of disturbances described in $\$ 16$ with what is disclosed by anxiety might be useful. Let us begin with the disturbances of $\$ 16$.

When things become unavailable, a double process commences. On the one hand, the availableness of the equipment (its worldly character) becomes manifest in the very moment of its withdrawal and, on the other hand, the sheer presence-at-hand of equipment announces itself. This important statement needs further explication. First, we must clarify what presence-at-hand means in the above statement. Being present-at-hand (in German: "Vorhandensein") means the ontological mode of things as detached, decontexualized and isolated objects. Following the above statement we start to see things as isolated objects with no embeddedness in a nexus of equipment in situations in which the context is at the point of breaking down. Two things must be considered at the same time. The context shows up at the very moment of its decontexualizing, and the decontexualized announces itself when the context breaks down. Nevertheless, we must be careful: What actually fades in the moment of disturbance is the readiness-to-hand of a specific equipment. To give an example: If a hammer gets

\footnotetext{
5 In my opinion, the English translation of the German word "Befindlichkeit" into "state-of-mind" is not appropriate. Dahlstrom (2001: 293), for example, proposes "disposedness" as a translation for "Befindlichkeit" which is more suitable.
} 
destroyed, it is the hammer with regard to its embeddedness in an equipment-whole or with regard to its worldly character that comes into view. Now the hammer shows itself in its pure presence-at-hand. That means that it is not the world itself that comes into focus; it is only the equipment with regard to its worldly character (Heidegger 1962: 104). For the world to come into focus, it must withdraw itself. As we have seen, this happens in the mood of anxiety. It is above all in the state of anxiety that we come face to face with the impending loss of significance of all entities within-the-world in total. This is why we in this mood get a phenomenological confirmation of the manifestness of being as a whole. A comparison with the phenomenon of disturbance as it is described in $\S 16$ of Being and Time shows that whereas the disturbances in $\$ 16$ of Being and Time are a case of a breakdown within the referential context, anxiety is a breakdown of the whole referential context as such. Only in the face of the nullity of all our holistic coping does the world reveal itself as such.

In summary, after all of these different remarks concerning the role of disturbances and anxiety, we have found a satisfying answer to the first question posed at the beginning of this paper. The question was how humans-in contrast to animals-have direct access to things as things. The answer is that only when faced with the total breakdown of the referential context (as experienced in the mood of anxiety) does the being reveal itself as such as a whole.

However, now I must pose a second question: How can the hidden side of things be directly disclosed (and not washed away in the course of this disclosure)? How can things hide in such a way that this hiddenness can be immediately seen or perceived? The answer to this question results immediately from the answer to the first question: The subject of the first question was how humans have access to entities as entities. As already mentioned, Heidegger's answer is: "the uncoveredness of entities withinthe-world is grounded in the world's disclosedness" (Heidegger 1962: 263). Such a world disclosedness in turn shows up in the disposedness of anxiety. Confronted with the loss of all of our familiarity with the world human beings face, first and foremost, the "manifestness of beings as such as a whole" (Heidegger 1995: 284). In the moment of the annihilation of all of our familiar routes in the world human beings learn simultaneously that everything that is discovered contains a vestige of unfamiliarity, of alienness. ${ }^{6}$ The announcement of the world and the experience of its annihilation are complementary factors that mutually reinforce one another.

Now it should be clear what is meant by the hidden side of objects and other people. What is being referred to is the side that is not "environmentally ready-tohand". The hidden side of things is things deprived of their meaning. Therefore, "Beings are not annihilated by anxiety" (Heidegger 1998: 90). In contrast, what is

\footnotetext{
${ }^{6}$ With this experience in mind, how things can cover up or disguise themselves and how a person is capable of immediately perceiving this disguisement can be phenomenologically shown. Smith (2007: 174) brought up a similar consideration by trying to answer Tugendhat's question how Heidegger's openness could also be wrong "in a critical sense" through Heidegger's existential analysis of death. Smith (2007: 175) writes: “As authentic, Dasein confronts death - Dasein's inability-to-be in the world - or in the sense relevant here, the breakdown of a world-disclosure and the practices that opened it. That is, only in the mode of authenticity does Dasein recognize that its world-disclosure is not an absolute one, that its disclosure may have left something out".
} 
annihilated is their significance. Only against the background of the annihilation of the meaningfulness of objects, can we experience them as meaningful objects.

\section{Detached Rationality and the Disclosure of the Hiddenness of being}

To summarize the above, it can be said that Heidegger's phenomenology includes an experience of alienness when we encounter other entities. We do not have only a direct relationship to things. On the contrary, this immediate relationship is constitued against the backdrop of a constant threat of the withdrawal of all things that are environmentally available. In contrast to the "Cartesian model" in which the natural world of objects can be opened by only an indirect cognitive process, that averted side of things is, according to Heidegger's phenomenology, an integral part of the human experience. However, how is it possible that the beings we encounter in our everyday life mutate into present-at-hand "objects" situated in a not immediately perceptible "outer" world? In short, how does detached rationality come to the fore? To answer this question, we must examine the different aspects of Heidegger's understanding of disturbance and anxiety once again.

Let us remember that the phenomenon of disturbance has two aspects. The available is decontextualized - the "pure presence-at-hand announces itself in such equipment" (Heidegger 1962: 103) — and at the very moment when availableness recedes, the worldliness of the available (its context) appears. This is possible only because availableness does not disappear at the moment of decontextualization but rather takes its leave "in the conspicuousness of the unusable" (Heidegger 1962: 104). It is important to note that Heidegger describes disturbance as an ongoing process and not as a finished state. In the ongoing process of decontextualization, the decontextualized objects present-at-hand do not become completely detached from human experience, but rather can be seen in the light of the available as its other side. Therefore, the two aspects of disturbance described in the foregoing discussion - the appearance of availableness and the simultaneous announcement of occurrentness - are two facets of the same event.

The same two aspects occur in connection with the phenomenon of anxiety (the breakdown of the referral relationship as such). In anxiety the "everyday familiarity" collapses (Heidegger 1962: 233), and the sheer presence of things in the world (in German: "Vorhandenheit") appears in its "empty mercilessness" (Heidegger 1962: 393). At the same time, however, anxiety (due to the insignificance of everything that can be encountered within the world) first discloses the world as a world (Heidegger 1962: 232). It is noteworthy to emphasize in this context that the presentat-hand shows up not only in cases of disturbance but also in the mood of anxiety. It occurs when all things are deprived of their meaning. ${ }^{7}$ Nevertheless, those

\footnotetext{
7 Disturbance (a kind of local breakdown) and anxiety (global breakdown) are two different aspects of human existence, though they are interrelated. Unfortunately Heidegger himself never worked out how they are connected to each other. In my opinion, anxiety is a structural necessity of Dasein's being-inthe-world (an "existential") whereas disturbance is only an "existentiell" possibility. That "existentiell" possibility, however, is nested into anxiety, it depends on it. Disturbance as a breakdown within the equipment whole presupposes a foregoing disclosure of the equipment whole - which in turn is possible only in the mood of anxiety.
} 
arguments alone are not a satisfactory answer to the question of how detached rationality comes to the fore.

Considering the previous explanations concerning disturbance and anxiety we must hold that neither an ongoing state of an absorbed and nonconceptual coping nor a complete decontextualization of our embodied practice into a decontextualized "object" and an equally decontextualized "subject" corresponds to the specific way of being of humans. Nevertheless, how is it possible that the human being understands himself as a "subject" that is set apart from an independent "outer" world? How does it come to pass that the beings that we encounter in our everyday life mutate into present-at-hand 'objects' situated in a not immediately perceptible "outer" world? The answer to this question is not easy. Relevant information is lacking in the philosophy of Heidegger. We can therefore only speculate in this respect.

How the experience of alienness changes into a detachment of all innerworldy beings from human experience might be answered in the following way. Detached rationality arises if decontextualization as a process coagulates as a finished result, when the context finally takes its leave and the sheer presence of things can no longer show up against the backdrop of a familiar referral context. If it reaches the point of a complete disappearance of the context, the decontexualization is no longer seen as a deficiency, the withdrawal of the available falls as withdrawal into oblivion and instead of seeing the sheer presence of objects as a withdrawal of availableness, it becomes an independent entity, detached from all human experience. ${ }^{8}$

We can illustrate these rather abstract reflections with the following parable. An farmer who is expelled from his land as the result of a military conflict begins to realize the real meaning of "being at home" only in the course of his expulsion. "Being at home" is normally a pattern of numerous inconspicuous reference points that make up the daily world of the farmer. Some of these reference points might be as follows: Where can I buy fodder? Where can I meet other people? Where should my children go to school? How must I deal with administrative channels? This context of reference points makes up the world of the farmer so inconspicuously that he normally does not recognize it. Now let us suppose that in a further step our farmer-after a number of years-finds new land in a foreign country, resumes farming, and settles down with his family. The more familiar he becomes with his new life and the more the earlier expulsion recedes into the background, the more the memory of his old world begins to dim. However, at the very moment in which the process of expulsion comes to an end, all those reference points that previously made up the world in his old country decontextualize into context-free facts without further relevance for the farmer. What I want to demonstrate with this example is the following: The meaning of "being at home" becomes apparent only in the course of the expulsion-not before (before the expulsion the farmer does not take deliberate

\footnotetext{
${ }^{8}$ I must admit that this turn of the available into a present-at-hand, independent entity does not sufficiently explain "the ontological genesis of the theoretical attitude" (Heidegger 1962: 408). It is only the first, albeit important, precondition for the genesis of the theoretical attitude that actually emerges in the course of a longer ongoing process. In order to look at "the ready-to-hand thing (...) as something present-at-hand" (Heidegger 1962: 412) the understanding of Being has to switch completely.
} 
notice of his world) but also not afterwards (when the expulsion comes to an end the context will have faded). It is at the very moment of the expulsion-the transitional period of the inconspicuous context into its disintegration-that the awareness of what "being at home" means emerges. "Being at home" announces itself while it is expiring—not after it has expired.

\section{Conclusion}

At the beginning of this paper I argued that Heidegger's Being-in-the-World can offer a "third way" beyond the limits of mindless coping and detached rationality. To see why, we must simply keep in mind the dialectic of the breakdown of significance and the disclosure of the world described above. If this dialectic makes up a structural necessity of Dasein's Being-in-the-World, then neither mindless coping nor detached rationality can be achievable separate states of human existence. They are at best extreme poles, tendencies in human life.

The reinterpretation of the human world as an occurrent totality of entities deprived of meaning is, in the face of the complementary role of the announcement of the world and its annihilation only an extrapolation-a fiction that transcends all human experience. Even the idea of a being as an entity detached from human experience lives in the fleeting memory of a context that has faded away. Conversely, any breaks in our familiar referral context are also faced with the constant danger of slipping into oblivion and solidifying any entity into a sheer decontextualized extant object. Instead of dreaming of an earthly paradise in which humans live in close communion with things they take care of, it is necessary to understand the internal dynamics and the interplay between familiarity and alienness, between disclosure and withdrawal, and between decontextualization and context. For this is the human condition.

Acknowledgements Open access funding provided by University of Innsbruck and Medical University of Innsbruck.

Open Access This article is licensed under a Creative Commons Attribution 4.0 International License, which permits use, sharing, adaptation, distribution and reproduction in any medium or format, as long as you give appropriate credit to the original author(s) and the source, provide a link to the Creative Commons licence, and indicate if changes were made. The images or other third party material in this article are included in the article's Creative Commons licence, unless indicated otherwise in a credit line to the material. If material is not included in the article's Creative Commons licence and your intended use is not permitted by statutory regulation or exceeds the permitted use, you will need to obtain permission directly from the copyright holder. To view a copy of this licence, visit http://creativecommons.org/licen ses/by/4.0/. 


\section{References}

Dahlstrom, D. O. (2001). Heidegger's concept of truth. Cambridge: Cambridge University Press.

Dreyfus, H. L. (1991). Being-in-the-World: A commentary on Heidegger's Being and Time, division I. Cambridge, MA: MIT Press.

Dreyfus, H. L. (1992). What computers still can't do. A critique of artificial reason. Cambridge, MA: MIT Press.

Dreyfus, H. L. (2005). Overcoming the myth of the mental: How philosophers can profit from the phenomenology of everyday expertise. Proceedings and Addresses of the American Philosophical Association, 79(2), 47-65.

Dreyfus, H. L. (2007). The return of the myth of the mental. Inquiry, 50(4), 352-365.

Dreyfus, H. L. (2009). How representational cognitivism failed and is being replaced by body/world coupling. In K. Leidlmair (Ed.), After cognitivism (pp. 39-73). Dordrecht: Springer.

Duits, R. (2007). On Tugendhat's analysis of Heidegger's concept of truth. International Journal of Philosophical Studies, 15(2), 207-223.

Fräntzki, E. (1987). Von der Un-verborgenheit. Fridolin Wiplingers Bericht von einem Gespräch mit Martin Heidegger. Pfaffenweiler: Centaurus-Verlagsgesellschaft.

Haugeland, J. (1998). Having thought. Essays in the metaphysics of mind. Cambridge: Harvard University Press.

Heidegger, M. (1962). Being and Time (J. Macquarrie \& E. Robinson, trans.). Oxford: Basil Blackwell.

Heidegger, M. (1971). The origin of the work of art. In Martin Heidegger. Poetry, language, thought (A. Hofstadter, trans.), (pp. 15-86). New York: Harper \& Row.

Heidegger, M. (1988). The basic problems of phenomenology (A. Hofstadter, trans). Bloomington: Indiana University Press.

Heidegger, M. (1992). Parmenides (A. Schuwer, \& R. Rojcewicz, trans). Bloomington: Indiana University Press.

Heidegger, M. (1995). The fundamental concepts of metaphysics. World, finitude, solitude (W. McNeill, \& N. Walker, trans.). Bloomington: Indiana University Press.

Heidegger, M. (1998). What is metaphysics? In McNeill, W. (ed.) Martin Heidegger. Pathmarks (D. F. Krell, trans.) (pp. 82-96). New York: Cambrige University Press.

Overgaard, S. (2002). Heidegger's concept of truth revisited. Nordic Journal of Philosophy, 3(2), 73-90.

Perner, S. (1991). Understanding the representational mind. Cambridge: MIT Press.

Schear, J. K. (2013). Mind, reason, and Being-in-the-World. The McDowell-Dreyfus Debate. London and New York: Routledge.

Smith, A. D. (2002). The problem of perception. Cambridge: Harvard University Press.

Smith, W. H. (2007). Why Tugendhat's critique of Heidegger's concept of truth remains a critical problem. Inquiry, 50(2), 156-179.

Tugendhat, E. (1970). Der Wahrheitsbegriff bei Husserl und Heidegger. Berlin: Walther de Gruyter \& Co.

Wheeler, M. (2005). Reconstructing the cognitive world. The Next Step. Cambridge: MIT Press.

Publisher's Note Springer Nature remains neutral with regard to jurisdictional claims in published maps and institutional affiliations. 